\title{
Effects of Different Mixture Ratios of Methanol-Diesel on the Performance Enhancement and Emission Reduction for a Diesel Engine
}

\author{
Zhiqing Zhang ${ }^{1,2} \oplus$, Jie Tian ${ }^{1,2}$, Jiangtao Li ${ }^{1,2}$, Hongchen $\mathrm{Ji}^{1,2}$, Dongli Tan ${ }^{2,3}$, Jianbin Luo ${ }^{1,2, *} \mathbb{C}$, Yuxiu Jiang ${ }^{4}$, \\ Dayong Yang ${ }^{1}$ and Shuwan Cui ${ }^{1}$ \\ 1 School of Mechanical and Transportation, Guangxi University of Science and Technology, \\ Liuzhou 545006, China; zhangzhiqing@gxust.edu.cn (Z.Z.); 221055068@stdmail.gxust.edu.cn (J.T.); \\ 221055037@stdmail.gxust.edu.cn (J.L.); 212037705@stdmail.gxust.edu.cn (H.J.); dyyang@gxust.edu.cn (D.Y.); \\ swcui@gxust.edu.cn (S.C.) \\ 2 Institute of the New Energy and Energy-Saving \& Emission-Reduction, Guangxi University of Science and \\ Technology, Liuzhou 545006, China; tandongli@gxust.edu.cn \\ 3 Research Center of Guangxi Industry High-Quality Development, Guangxi University of Science and \\ Technology, Liuzhou 545006, China \\ 4 School of Vehicle Engineering, Guangxi Industrial Vocational and Technical College, Nanning 530001, China; \\ jyx1976@163.com \\ * Correspondence: luojianbin@gxust.edu.cn
}

check for

updates

Citation: Zhang, Z.; Tian, J.; Li, J.; Ji, H.; Tan, D.; Luo, J.; Jiang, Y.; Yang, D.; Cui, S. Effects of Different Mixture

Ratios of Methanol-Diesel on the Performance Enhancement and Emission Reduction for a Diesel Engine. Processes 2021, 9, 1366. https://doi.org/10.3390/pr9081366

Academic Editors:

Alessandro D'Adamo and Jiaqiang E

Received: 24 July 2021

Accepted: 2 August 2021

Published: 4 August 2021

Publisher's Note: MDPI stays neutral with regard to jurisdictional claims in published maps and institutional affiliations.

Copyright: (c) 2021 by the authors. Licensee MDPI, Basel, Switzerland. This article is an open access article distributed under the terms and conditions of the Creative Commons Attribution (CC BY) license (https:// creativecommons.org/licenses/by/ $4.0 /)$.

\begin{abstract}
To improve the combustion and emission characteristics of diesel engines, methanol-diesel fuels with different mixing ratios (DM0, DM10, DM20, DM30, and DM40) were used to investigate the effects of methanol addition on the combustion and emission of a four-stroke diesel engine in terms of cylinder pressure, brake power, brake-specific fuel consumption, and nitrogen oxides, soot, and carbon monoxide emissions. Firstly, an improved entire diesel engine model was developed using AVL-BOOST software and validated by the experimental results. The results showed that the increase of methanol content in the fuel mixture had a negative impact on the performance characteristic of the diesel engine, but significantly improved the emission characteristic of the diesel engine. With the methanol ratio in the mixed fuel increased to $10 \%, 20 \%, 30 \%$, and $40 \%$, the cylinder pressure of the engine increased by $0.89 \%, 1.48 \%, 2.29 \%$, and $3.17 \%$, respectively. However, the power decreased by $3.76 \%, 6.74 \%, 11.35 \%$, and $15.45 \%$, the torque decreased by $3.76 \%, 6.74 \%, 11.35 \%$, and $15.45 \%$, respectively, and the brake specific fuel consumption increased by $3.77 \%, 6.92 \%, 12.33 \%$, and $17.61 \%$, respectively. In addition, with the methanol ratio in the mixed fuel increased to $10 \%$, $20 \%, 30 \%$, and $40 \%$, the carbon monoxide emission decreased by $21.32 \%, 39.04 \%, 49.81 \%$, and $56.59 \%$ and the soot emission decreased by $0.25 \%, 8.69 \%, 16.81 \%$, and $25.28 \%$, respectively. Therefore, the addition of methanol to the fuel can improve the combustion and emission characteristics of the engine.
\end{abstract}

Keywords: methanol; diesel engine; diesel oxidation catalyst; AVL-BOOST; performance

\section{Introduction}

Diesel engines are widely used in passenger and cargo transportation and engineering power because of their good economy [1] and reliability [2]. They make a significant contribution to industrial development and economic progress. However, the combustion of diesel engines emits many pollutants, including carbon monoxide (CO), hydrocarbons (HC), nitrogen oxides $\left(\mathrm{NO}_{\mathrm{x}}\right)$, particulate matter $(\mathrm{PM})$, etc. [3]. Thus, the pollutant gas from diesel engines seriously pollutes the environment and seriously harms the public's health [4]. The two primary pollutants in a diesel engine are $\mathrm{PM}$ and $\mathrm{NO}_{\mathrm{x}}$, and the relationship between them is a trade-off [5]. The single internal purification or aftertreatment technology is challenging to reduce $\mathrm{PM}$ and $\mathrm{NO}_{\mathrm{x}}$ emissions [6]. Therefore, the exhaust 
gas aftertreatment system has become an integral part of diesel vehicles [7]. Only the combination of internal purification technology and aftertreatment technology can meet the increasingly stringent emission regulations [8]. Facing the problem of global environmental degradation and the energy crisis, how to effectively reduce the emissions of diesel engines and how to look for renewable fuels needs to be solved in the development of society. Many researchers found that alcohol fuels and biodiesel played an essential role in alleviating environmental pollution and energy crises. These alternative fuels can reduce our dependence on fossil energy and reduce $\mathrm{CO}$ and $\mathrm{HC}$ emissions [9]. As an economical alternative fuel with clean combustion characteristics, methanol is considered one of the most promising alternatives to diesel fuel. Because of its high-octane number, methanol can be used directly in spark-ignition engines [10]. Then, methanol has a higher heat of vaporization value, which will produce a cooling effect when forming the mixture, resulting in a decrease in inlet temperature. In addition, compared with other hydrocarbon fuels, methanol has a higher oxygen content and laminar flame speed (LFS). Moreover, methanol is easy to produce and can be made from renewable energy sources and fossil fuels, such as natural gas and coal [11]. Therefore, mixing methanol with other hydrocarbons can improve combustion efficiency and reduce combustion temperature.

In recent years, the application of methanol fuel in diesel engines has become a hot topic of research for many researchers. Yao et al. [12] studied methanol-diesel compound fuel (DMCC) and showed that DMCC reduced soot and $\mathrm{NO}_{\mathrm{x}}$ emissions, but increased $\mathrm{HC}$ emissions. Berber [13] studied the effects of adding methanol to diesel fuel on the engine. The results showed that the addition of methanol reduced engine performance by about $12-13 \%$, but reduced $\mathrm{CO}_{2}$ and $\mathrm{CO}$ emissions. Zang et al. [14] used a modified KIVA-3V program coupled with the CHEMKIN solver to simulate the combustion and emission of a diesel/methanol dual fuel (DMDF) engine. The results showed that the ignition delay time in the DMDF mode was longer than that in the diesel mode. Moreover, the soot and $\mathrm{NO}_{\mathrm{x}}$ emissions were significantly reduced. In summary, methanol is considered a promising alternative to conventional fuels due to its good combustion characteristics, sustainability, and easy availability potential.

In addition, aftertreatment technology is also one of the most effective ways to reduce pollutant emissions. Today, the leading diesel engine exhaust emission aftertreatment technologies include [15]: diesel oxide catalysts (DOCs) to reduce hydrocarbons and carbon monoxide, diesel particulate filters (DPFs) to reduce particulate matter emission, and selective catalytic reduction (SCR) to reduce nitrogen oxides emission, etc. However, most aftertreatment systems produce exhaust back pressure (EBP) [16], affecting engine performance, as will be detailed in the results and discussion. In the aftertreatment technology of diesel engine exhaust, a DOC is installed in the diesel engine's exhaust pipe, which is the first step of the whole aftertreatment of the diesel engine. A DOC has a honeycomb monolith shape with high cell density (large surface area) [17] and suitable catalytic material loading such as Pt [18] and/or Pd [19]. The DOC oxidizes CO [20], $\mathrm{HC}$ [21], and the organic fraction of diesel particles to harmless water and $\mathrm{CO}_{2}$. In addition, it also oxidizes nitric oxide (NO) to nitrogen dioxide $\left(\mathrm{NO}_{2}\right)$ [22]. It promotes continuous regeneration of downstream diesel particulate filters and improves the conversion efficiency of $\mathrm{NO}_{\mathrm{x}}$ via selective catalytic reduction at low temperatures [23].

Engine combustion is a complex and variable physicochemical process. To improve combustion efficiency and reduce the cost of diesel engines [24], numerical methods are often used as an alternative [25]. They are widely used as tools for improvement and alternatives in the process of engine design with limited resources [26]. The designer only needs to select an appropriate model and input the diesel engine parameters [27]. Then the designer can make a preliminary demonstration and simulation of the model. This is because modeling and simulation software provides a platform with a design [28]. For example, Lan et al. [29] developed an AMESim model to analyze the amount of fuel injected into a diesel fuel system. Nikzadfar et al. [30] also investigated the contribution of different operating parameters on the heat release rate (HRR) and emission performance by 
using a neural network. Yang et al. [31] studied the effects of fuel composition on the HRR and found that the HRR greatly affected the ability to perform partial fuel stratification strategies.

Typically, the zero-dimensional and double zone combustion simulation models of diesel engines are investigated by using GT-Power and AVL-BOOST software, respectively. Yu et al. [32] developed an improved heat transfer model using AVL-BOOST software to study diesel engine combustion and emission characteristics. The results showed that, compared with the Woschni 1978 model, the prediction accuracy of the improved model was higher. Tan et al. [33] established a new heat transfer model using a modular method in AVL-BOOST software to study the effects of swirl and boiling heat transfer on performance enhancement and emission reduction of a medium diesel engine fueled with biodiesel. The results showed that boiling heat transfer occurs, especially in the high-temperature area, and the improved model was reliable and accurate. The one-dimensional models are simpler, faster, and include more detailed physical models. In general, more advanced models such as combustion, heat transfer, and pollutant formation processes should be used to simulate and improve the accuracy of the calculations. However, as an excellent alternative to fossil energy sources, methanol is characterized by low pollutant emissions and high thermal efficiency. Therefore, it is crucial to study the effects of methanol on engine combustion and emission characteristics.

As previously described, methanol-diesel fuels have significant advantages in physicochemical properties and combustion characteristics. Therefore, in-depth theoretical and experimental studies are needed when methanol-diesel fuels are widely used in engines due to their efficient combustion. In this paper, an improved entire diesel engine model was developed in AVL BOOST software. To evaluate the practicality of methanol-diesel fuel, different fuel mixture ratios (DM0, DM10, DM20, DM30, and DM40) were used to simulate the cylinder combustion process in a diesel engine. Experiments were performed on a four-cylinder, four-stroke diesel engine, and the improved model was validated under different engine conditions. Finally, the effects of using different methanol-diesel mixture ratios as fuel on the combustion and emission characteristics of the diesel engines were also investigated and compared.

\section{Methods and Model Validation}

AVL BOOST software(v2016) is an engine process simulation software that complies with engine industry standards. The models accurately simulate the combustion processes of gasoline, diesel, and dual-fuel engines. To simplify the simulation process, the intake and exhaust are considered as the ideal gases. The main mathematical models are as follows.

\subsection{An Improved Entire Diesel Engine Simulation Model}

\subsubsection{Intake and Exhaust Pipe Model}

In engine simulation, the flows in intake and exhaust pipes are unstable, so the intake and exhaust pipes model can be calculated using the finite volume method. The specific calculation process can be expressed as follows [34]:

$$
\begin{gathered}
\frac{\mathrm{d} m}{\mathrm{~d} t}=\sum_{\text {front }} \dot{m} \\
\frac{\mathrm{d}(m e)}{\mathrm{d} t}=p \frac{\mathrm{d} V}{\mathrm{~d} t}+\sum_{\text {front }}(\dot{m} H)-h_{g} A\left(T_{\text {gas }}-T_{\text {wall }}\right) \\
\frac{\mathrm{d}(m H)}{\mathrm{d} t}=\sum_{\text {front }}(\dot{m} H)+V \frac{\mathrm{d} p}{\mathrm{~d} t}-h_{g} A\left(T_{\text {gas }}-T_{\text {wall }}\right) \\
\frac{\mathrm{d}(\dot{m})}{\mathrm{d} t}=\frac{A \mathrm{~d} p+\sum_{\text {front }}(\dot{m} u)-4 f \frac{\rho u^{2} \mathrm{~d} x A}{2 D}-C_{p}\left(\frac{1}{2} \rho u^{2}\right) A}{\mathrm{~d} x}
\end{gathered}
$$


where $m$ is the mass of the volume considered, $g ; \sum_{\text {front }}$ means to sum on the boundary; $\dot{m}$ is the mass flow through the boundary, $\mathrm{g} / \mathrm{h} ; \mathrm{p}$ is the pressure, $\mathrm{Pa} ; V$ is the volume, $\mathrm{m}^{3} ; H$ is the total enthalpy $(H=e+p / \rho), \mathrm{J} ; \rho$ is the density, $\mathrm{g} / \mathrm{m}^{3} ; e$ is the total internal energy (internal energy plus kinetic energy), $\mathrm{J} ; h_{g}$ is the convective heat transfer coefficient, $\mathrm{J} /\left(\mathrm{m}^{2} \mathrm{~s}^{\circ} \mathrm{C}\right) ; A$ is the cross-flow area, $\mathrm{m}^{2} ; T_{\text {gas }}$ is the gas temperature, $\mathrm{K} ; T_{\text {wall }}$ is the wall temperature, $\mathrm{K} ; u$ is the velocity at the boundary of the volume, $\mathrm{m} / \mathrm{s} ; f$ is the surface friction coefficient; $D$ is the equivalent diameter, $\mathrm{m} ; C_{p}$ is the head loss coefficient; $d p$ is the pressure difference acting across $d x, \mathrm{~Pa}$; and $d x$ is the thickness of the element in the direction of the flow near the boundary, $\mathrm{m}$.

\subsubsection{Cylinder Model}

The combustion and heat transfer processes of the cylinder follow certain rules. The basic equations of the working process of the cylinder are as follows:

(1) Energy conservation equation:

$$
\mathrm{d} U=\mathrm{d} W+\sum \mathrm{d} Q_{i}+\sum_{j} h_{j} \cdot \mathrm{d} m_{j}
$$

where $U$ is the internal energy of the system, $\mathrm{J} ; W$ is the mechanical work acting on the piston, $\mathrm{J} ; Q_{i}$ is the heat exchanged through the boundary of the system, $\mathrm{J} ; h_{j}$ is the specific enthalpy, J; and $h_{j} \cdot d m_{j}$ is the energy that mass $d m_{j}$ brings into or brings out of the system, J.

(2) Mass conservation equation:

$$
\frac{\mathrm{d} m}{\mathrm{~d} \theta}=\frac{\mathrm{d} m_{A}}{\mathrm{~d} \theta}+\frac{\mathrm{d} m_{B}}{\mathrm{~d} \theta}+\frac{\mathrm{d} m_{C}}{\mathrm{~d} \theta}
$$

where $m$ is the mass of fuel in the cylinder, $\mathrm{g} ; m_{A}$ is the mass of air flowing into the cylinder, $\mathrm{g} ; m_{B}$ is the mass of exhaust gas leaving the cylinder, $g ; m_{C}$ is the instantaneous mass of fuel injected into the cylinder, $\mathrm{g}$; and $\theta$ is the crank angle, ${ }^{\circ}$.

In addition, if the cycle injection quantity of the diesel engine is $g_{h}$, the fuel percentage in the cylinder is $X=m_{c} / g_{h}$. Thus, Equation (6) can be transformed as follows:

$$
\frac{\mathrm{d} m}{\mathrm{~d} \theta}=\frac{\mathrm{d} m_{A}}{\mathrm{~d} \theta}+\frac{\mathrm{d} m_{B}}{\mathrm{~d} \theta}+g_{h} \cdot \frac{\mathrm{d} X}{\mathrm{~d} \theta}
$$

(3) Equation of state of an ideal gas:

$$
p V=m R T
$$

where $p$ is the pressure of gas in the cylinder, $\mathrm{Pa} ; V$ is the volume of gas in the cylinder, $\mathrm{m}^{3}$; $R$ is the gas constant; and $T$ is the temperature of the gas in the cylinder, $\mathrm{K}$.

\subsubsection{Combustion Model}

AVL-BOOST software provides multiple combustion models to simulate the combustion process under different conditions, including the Vibe combustion heat release model, FRACTAL combustion heat release model, AVL MCC combustion heat release model, etc. In this paper, the combustion of a diesel engine is simulated using the AVL MCC combustion model. This model is used to calculate the combustion process of a direct injection diesel engine. It can predict the combustion heat release rate and $\mathrm{NO}_{\mathrm{x}}$ emission based on the amount of fuel injected in the cylinder and the turbulent kinetic energy formed by the fuel injection.

The MCC combustion model also considers the development of premixed combustion and diffusion combustion. The total combustion heat release rate is expressed as:

$$
\frac{\mathrm{d} Q_{\text {total }}}{\mathrm{d} \theta}=\frac{\mathrm{d} Q_{P M C}}{\mathrm{~d} \theta}+\frac{\mathrm{d} Q_{M C C}}{\mathrm{~d} \theta}
$$


where $Q_{\text {total }}$ is the combustion heat release rate, $\mathrm{J} / \mathrm{deg} ; Q_{P M C}$ is the total heat release rate of premixed combustion, $\mathrm{J} ; Q_{M C C}$ is the total heat release rate of diffusion combustion, J; and $\theta$ is the crank angle, ${ }^{\circ}$.

The total heat release rate for diffusion combustion is expressed as:

$$
\frac{\mathrm{d} Q_{M C C}}{\mathrm{~d} \theta}=C_{\text {comb }} \cdot\left(m_{F}-\frac{Q_{M C C}}{L C V}\right) \cdot\left(w_{\text {oxygen,available }}\right)^{C_{E G R}} \cdot C_{\text {Rate }} \cdot \frac{\sqrt{k}}{\sqrt[3]{V}}
$$

The actual heat release rate of premixed combustion is expressed as:

$$
\frac{\left(\frac{\mathrm{d} Q_{P M C}}{Q_{P M C}}\right)}{\mathrm{d} \theta}=\frac{6.908}{\Delta \theta_{c}} \cdot\left(m_{s}+1\right) \cdot\left(\frac{\theta-\theta_{t d}}{\Delta \theta_{c}}\right)^{m_{s}} \cdot \exp \left[-6.908 \cdot\left(\frac{\theta-\theta_{t d}}{\Delta \theta_{c}}\right)^{\left(\mathrm{m}_{s}+1\right)}\right]
$$

where $C_{\text {comb }}$ is the combustion constant; $m_{F}$ is the mass of fuel injected, $\mathrm{kg}$; $L C V$ is the combustion low calorific value, $\mathrm{kJ} /(\mathrm{kg}) ; w_{\text {oxygen, available }}$ is the mass fraction of oxygen in the mixture at the time of fuel injection, \%; $C_{E G R}$ is the EGR influence constant; $C_{\text {Rate }}$ is the mixing rate constant; $k$ is the local turbulent flow energy density, $\mathrm{m}^{2} / \mathrm{s}^{2} ; V$ is the cylinder volume, $\mathrm{m}^{3} ; m_{s}$ is the shape parameter; $\Delta \theta_{c}$ is the crank angle difference, ${ }^{\circ}$; and $\theta_{t d}$ is the start of combustion angle, ${ }^{\circ}$.

\subsubsection{Heat Transfer Model}

The heat transfer in the cylinder of the diesel engine is a highly complex process. Woschni1978 is mainly used to calculate the second-rate heat exchange coefficient in the high-pressure cycle cylinder of the engine full-load operating cylinder. In contrast, the modified woschni1990 heat transfer model is mainly used to simulate part load heat transfer more accurately. A heat transfer model based on the Woschni model (Hohenberg heat transmission model) is used in this study, and the form of the equation is simpler:

$$
\alpha_{w}=130 V_{a}^{-0.06} \cdot p_{c}^{0.8} \cdot T_{c}^{-0.4} \cdot\left(c_{m}+1.4\right)^{0.8}
$$

where $\alpha_{w}$ is the isothermal exchange coefficient; $V_{a}$ is the volume of the actual cylinder, $\mathrm{mm}^{3} ; p_{c}$ is the pressure in the cylinder, $\mathrm{MPa} ; T_{c}$ is the temperature in the cylinder, $\mathrm{K}$; and $c_{m}$ is the average piston speed, $\mathrm{m} / \mathrm{s}$.

\subsubsection{Turbocharging Mathematical Model}

In this paper, the full model calculation mode is used. It can be used to simulate turbocharger performance, such as speed, efficiency, and air discharge.

The parameters of the compressor are measured in a particular atmospheric state, and the compressor operates in different environments, which are affected by the inlet air state. In actual use, similar parameters are used to draw the compressor characteristic curve. The reduced parameters are as follows:

Reduced flow rate:

$$
\dot{m}_{c o r}=\frac{\dot{m} \sqrt{T_{0, i n} / T_{\text {std }}}}{p_{0, \text { in }} / p_{\text {std }}}
$$

Reduced speed:

$$
n_{\text {cor }}=\frac{n_{T}}{\sqrt{T_{0, i n} / T_{\text {std }}}}
$$

where $\dot{m}$ is the mass flow rate, $\mathrm{kg} / \mathrm{s} ; T_{0, \text { in }}$ is the inlet gas temperature of the compressor, $\mathrm{K} ; T_{\text {std }}$ is the atmospheric temperature under standard conditions, $\mathrm{K} ; P_{0, \text { in }}$ is the inlet gas pressure of the compressor, $\mathrm{Pa} ; p_{s t d}$ is the atmospheric pressure under standard conditions, $\mathrm{Pa}$; and $n_{T}$ is the compressor speed, $\mathrm{r} / \mathrm{min}$. 


\subsubsection{Emission Model}

The Pattas and Hafner equation [35] is combined with the Zeldovich mechanism for mathematical modeling of $\mathrm{NO}_{\mathrm{x}}$ generation rates in AVL-BOOST, as described below:

$$
r_{N O}=C_{\text {PostProcMult }} \cdot C_{\text {KineticMult }} \cdot(2,0) \cdot\left(1-\alpha_{N O}{ }^{2}\right) \cdot\left(\frac{r_{1}}{1+\alpha \cdot A K_{1}}+\frac{r_{4}}{1+A K_{2}}\right)
$$

with,

$$
\begin{gathered}
\alpha_{N O}=\frac{C_{N O, a c t}}{C_{N O, e q u}} \cdot \frac{1}{C_{\text {KineticMult }}} \\
A K_{1}=\frac{r_{1}}{r_{2+} r_{3}} \\
A K_{2}=\frac{r_{4}}{r_{5+} r_{6}}
\end{gathered}
$$

where $r_{N O}$ is the reaction rate of $\mathrm{NO}_{x}$, mole $/ \mathrm{cm}^{3} ; C_{\text {PostProcMult }}$ is the post-processing multiplier of $\mathrm{NO}_{\mathrm{x}} ; \mathrm{C}_{\text {KineticMult }}$ is the kinetic multiplier of $\mathrm{NO}_{\mathrm{x}} ; \mathrm{C}_{i}$ is the molar concentration of $\mathrm{NO}_{\mathrm{x}}$, mole $/ \mathrm{cm}^{3}$; and $r_{i}$ is the reaction rate of the Zeldovich mechanism, mole $/ \mathrm{cm}^{3}$. The equation provided by Onorati et al. [36] is used for modeling $\mathrm{CO}$ formation:

$$
r_{C O}=C_{\text {Const }} \cdot\left(s_{1}+s_{2}\right) \cdot\left(1-\alpha_{C O}\right)
$$

with,

$$
\alpha_{\mathrm{CO}}=\frac{c_{C O, a c t}}{c_{C O, e q u}}
$$

where $r_{C O}$ is the reaction rate of $\mathrm{CO}, \mathrm{mole} / \mathrm{cm}^{3} ; C_{\text {const }}$ is the concentrations under equilibrium conditions of $\mathrm{CO}$, mole $/ \mathrm{cm}^{3} ; s_{i}$ is the reaction rate based on the model, mole $/ \mathrm{cm}^{3}$; and $c_{i}$ is the molar concentration of $\mathrm{CO}, \mathrm{mole} / \mathrm{cm}^{3}$. The equations provided by Schubiger et al. [37] are used for modeling soot formation:

$$
\begin{gathered}
\frac{\mathrm{d} m_{s, f}}{\mathrm{~d} t}=A_{s, f} \cdot \frac{\mathrm{d} m_{f b, d i f f}}{\mathrm{~d} t} \cdot\left(\frac{p_{a}}{p_{r e f}}\right)^{n_{1}} \cdot e^{\frac{E_{s, f}}{R_{m} \cdot T_{s}}} \\
\frac{\mathrm{d} m_{s, o}}{\mathrm{~d} t}=A_{s, o} \cdot \frac{1}{\tau_{\text {char }}} \cdot\left(m_{\text {soot }}\right)^{n_{2}} \cdot\left(\frac{p_{\mathrm{O}_{2}}}{p_{\mathrm{O}_{2}, \text { ref }}}\right)^{n_{3}} \cdot e^{\frac{E s, o}{R_{m} \cdot T_{s}}}
\end{gathered}
$$

where $\mathrm{d} m_{s, f} / \mathrm{d} t$ is the soot formation rate, $\mathrm{kg} / \mathrm{s} ; A_{s, f}$ is the parameter soot formation; $d m_{f b, d i f f} / d t$ is the combustion rate of diffusion combustion, $\mathrm{kg} / \mathrm{s} ; p_{a}$ is the pressure actual, $\mathrm{Pa} ; p_{\text {ref }}$ is the pressure reference, $\mathrm{Pa} ; E_{s, f}$ is the activation energy formation, $\mathrm{J} / \mathrm{mol} ; R_{m}$ is the gas constant, $\mathrm{KJ} / \mathrm{Kmol} \cdot \mathrm{K} ; T_{S}$ is the temperature, $\mathrm{K} ; d m_{s, o} / d t$ is the oxidation rate, $\mathrm{kg} / \mathrm{s} ; A_{s, o}$ is the parameter soot oxidation; $\tau_{\text {char }}$ is the mixing term; $m_{\text {soot }}$ is the actual soot mass, $\mathrm{kg}$; $\mathrm{po}_{2}$ is the partial pressure oxygen actual, $\mathrm{Pa} ; \mathrm{po}_{2, r e f}$ is the partial pressure oxygen reference, $\mathrm{Pa} ; E_{S, o}$ is the activation energy oxidation, $\mathrm{J} / \mathrm{mol}$; and $n_{1}, n_{2}, n_{3}$ are the model constants.

Moreover, the complex phenomenological model for the prediction of HC formation developed by AVL-BOOST is employed for modeling unburned hydrocarbons [38].

\subsection{Simulation Model Establishment of an Entire Diesel Engine}

To study the combustion and emission characteristics of the improved diesel engine, a one-dimensional simulation model of the diesel engine is established under the AVLBOOST environment. Figure 1 shows the layout of the entire diesel engine. The main parameters are set out in Table 1. During the exhaust stroke, the exhaust is exhausted, and a small portion flows into the turbine intake. The turbine drives the turbo compressor, which delivers the compressed air to the cooler. However, most of the exhaust gases are purified by aftertreatment systems (DOC, DPF, and SCR) and released directly into the air. 


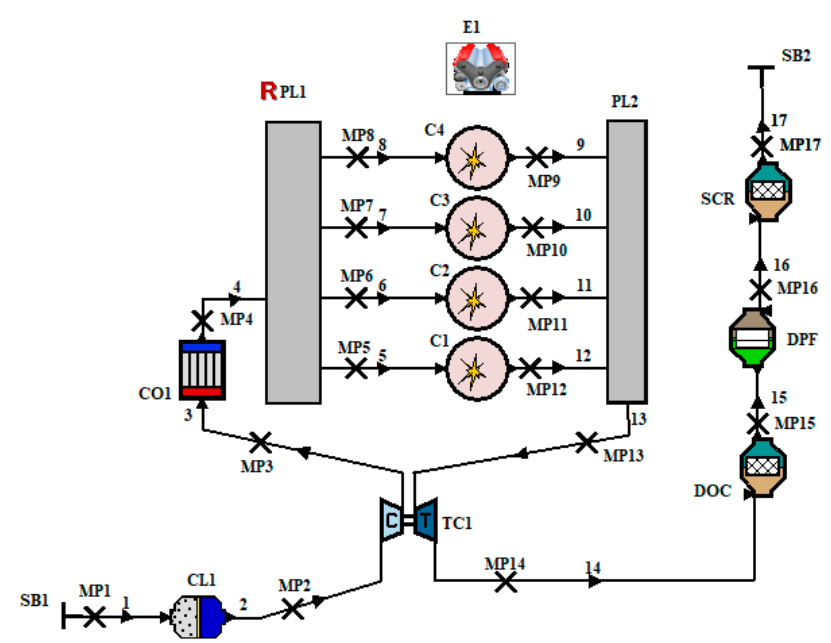

Figure 1. Simulation model of the entire diesel engine.

Table 1. Key parameters for diesel engines.

\begin{tabular}{ccc}
\hline Performance Index & Unit & Value \\
\hline Cylinder diameter & $\mathrm{mm}$ & 190 \\
Number of cylinders & - & 4 \\
Rate speed & $\mathrm{r} / \mathrm{min}$ & 4000 \\
Peak pressure & $\mathrm{MPa}$ & 12 \\
Rated power & $\mathrm{kW}$ & 220 \\
Mean effective pressure & $\mathrm{MPa}$ & 2.05 \\
Compression ratio & - & 14 \\
\hline
\end{tabular}

\subsection{Fuel Properties}

In the paper, four different methanol-diesel fuels $(10 \%, 20 \%, 30 \%$, and $40 \%$ methanol by volume) were investigated, where $10 \%$ methanol addition mixtures with $90 \%$ diesel by volume, $20 \%$ methanol addition mixtures with $80 \%$ diesel by volume, $30 \%$ methanol addition mixtures with $70 \%$ diesel by volume, $40 \%$ methanol addition mixtures with $60 \%$ diesel by volume, and pure diesel (DM0) were defined as DM10, DM20, DM30, and DM40, respectively. The detailed fuel physical properties are shown in Table 2 [39]. Moreover, according to ASTM D240 and ASTM D445, the kinematic viscosity and lower calorific were measured, respectively. Table 3 shows the list of measurements, the measurement range, and the accuracy.

Table 2. Main physical and chemical properties of diesel and methanol.

\begin{tabular}{ccc}
\hline Performance Index & Diesel & Methanol \\
\hline Latent heat of gasification $(\mathrm{KJ} / \mathrm{kg})$ & 260 & 1162.2 \\
Auto-ignition temperature $\left({ }^{\circ} \mathrm{C}\right)$ & 250 & 463 \\
Low calorific value $(\mathrm{MJ} / \mathrm{kg})$ & 42.5 & 20.1 \\
Cetane number & 51 & 3.8 \\
Stoichiometric air fuel ratio & 14.3 & 6.5 \\
Kinematic viscosity $\left(40^{\circ} \mathrm{C}\right)\left(\mathrm{mm}^{2} / \mathrm{s}\right)$ & 2.72 & 0.58 \\
\hline
\end{tabular}


Table 3. Lists of measurements, the measuring range, and accuracy.

\begin{tabular}{cccc}
\hline Measurements & Measuring Range & Accuracy & Uncertainty (\%) \\
\hline Cylinder pressure & $1-25 \mathrm{MPa}$ & $\pm 10 \mathrm{kPa}$ & \pm 0.5 \\
Exhaust gas temperature & $0-1000^{\circ} \mathrm{C}$ & $\pm 1{ }^{\circ} \mathrm{C}$ & \pm 0.25 \\
Brake power & - & $0.03 \mathrm{~kW}$ & \pm 0.03 \\
$\mathrm{HC}$ emission & $0-20,000 \mathrm{ppm}$ & $\pm 10 \mathrm{ppm}$ & \pm 0.11 \\
$\mathrm{NO}$ emission & $0-5000 \mathrm{ppm}$ & $\pm 10 \mathrm{ppm}$ & \pm 0.53 \\
Soot emission & $0-9 \mathrm{FSN}$ & $\pm 0.1 \mathrm{FSN}$ & \pm 2.8 \\
BSFC & - & $\pm 5 \mathrm{~g} / \mathrm{kW} \mathrm{h}$ & \pm 1.5 \\
CO emission & $0-10 \% \mathrm{vol}$ & $\pm 0.03 \%$ & \pm 0.32 \\
Air flow mass & $0-33.3 \mathrm{~kg} / \mathrm{min}$ & $\pm 1 \%$ & \pm 0.5 \\
Fuel flow measurement & $0.5-100 \mathrm{~L} / \mathrm{h}$ & $\pm 0.04 \mathrm{~L} / \mathrm{h}$ & \pm 0.5 \\
\hline
\end{tabular}

\subsection{Model Validation}

After using AVL-BOOST software to build the simulation model, the experimental validation results need to be verified if the improved model is applied to the simulation. The experiment was carried out, and the schematics of the experimental device are shown in Figure 2. A fuel consumption meter (FCMM-2) was used to measure brake-specific fuel consumption (BSFC). A combustion analyzer (AVL DEWE-2010CA) was used to monitor the diesel engine combustion. A Horiba MEXA (7100 DEGR) was used as an exhaust gas analyzer to measure nitrogen oxides, unburned hydrocarbons, carbon monoxide, and oxygen percentages. A smoke opacimeter (DiSmoke 4000) was used to detect the engine soot emission from the engine tailpipe. An ECU control system was used to control the electronically-controlled diesel engine. A hydraulic dynamometer was used for measuring the diesel engine load. In addition, the temperature, flow, and pressure were measured using suitable sensors.

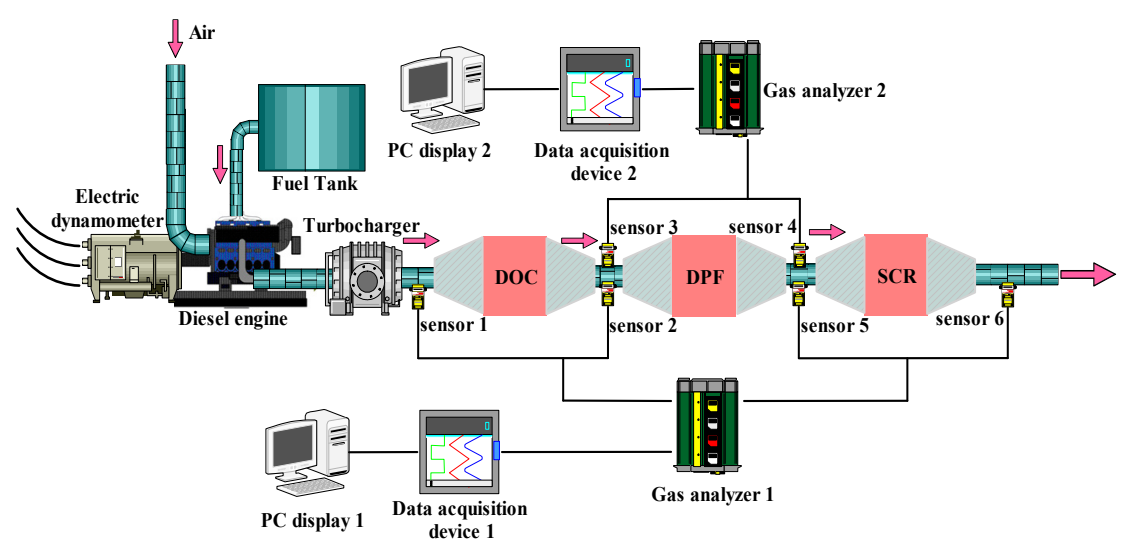

Figure 2. Schematic diagram of the experimental device.

In order to verify the model, a four-cylinder, four-stroke engine was employed to carry out the experiment. The engine was numerically simulated using methanol-diesel (DM0, DM10, DM20, DM30, and DM40) as the engine fuel. The DM0 fuel and DM10 fuel ( $10 \%$ methanol addition mixtures with $90 \%$ diesel by volume) were employed to verify the model. Figure 3 shows the cylinder pressure (see Figure 3a) and heat release rate (HRR) (see Figure 3b) under different fuel mixing ratios (DM0, DM10). The results showed that the simulation results of cylinder pressure and ignition time were consistent with the experimental results. The simulation results were in good agreement with the experimental results, which verified the correctness of the model. Therefore, the improved model can accurately predict the combustion characteristic of the engine. 

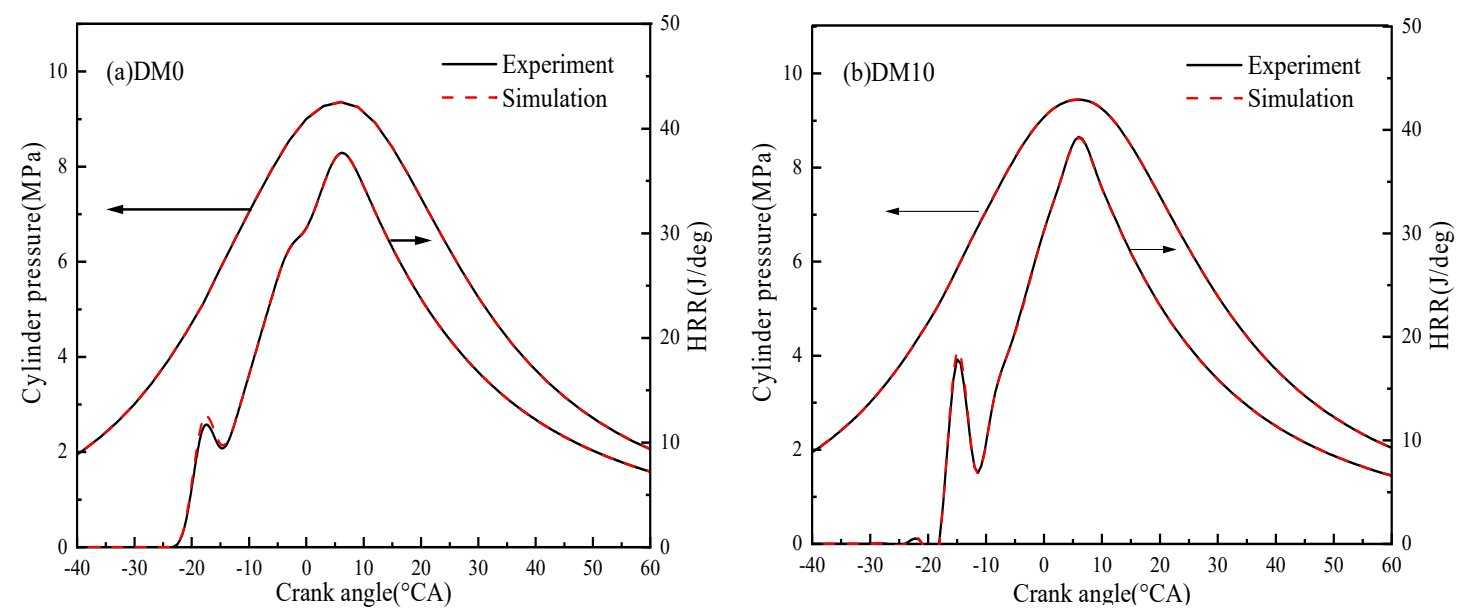

Figure 3. Comparison of cylinder pressure and HRR under different fuel mixing ratios.

\section{Results and Discussion}

The simulation experiment was carried out at the speed of 1000-4000 rpm. The effects of different ratios of methanol-diesel mixtures on engine performance and emission characteristics were studied in terms of cylinder pressure, cylinder temperature, brake-specific fuel consumption (BSFC), brake power, brake thermal efficiency (BTE), soot emission, $\mathrm{NO}_{\mathrm{x}}$ emission, $\mathrm{CO}$ emission, $\mathrm{HC}$ emission, and so on. In addition, the actual air-fuel ratio of pure diesel (DM0) was 14.355, that of 90\% diesel and 10\% methanol (DM10) was 13.755, that of $80 \%$ diesel and 20\% methanol (DM20) was 12.941, that of 70\% diesel and 30\% methanol (DM30) was 12.127, and that of 60\% diesel and 40\% methanol (DM40) was 11.313.

\subsection{The Engine Combustion Characteristic}

Figure $4 a-d$ shows the effect of methanol-diesel mixture with different ratios on engine in-cylinder pressure at different speeds. It can be seen that with the increase of the ratio of methanol, the maximum combustion pressure of the diesel engine increases gradually. The results show that the maximum cylinder pressure for DM10, DM20, DM30, and DM40 mixes is higher than that of pure diesel DM0. For example, when the engine speed was $4000 \mathrm{rpm}$, the cylinder pressure increases by $0.89 \%, 1.48 \%, 2.29 \%$, and $3.17 \%$ when the ratio of methanol in the fuel mixture increased to $10 \%, 20 \%, 30 \%$, and $40 \%$, respectively. In addition, the ignition delay of DM40 is delayed by about $3{ }^{\circ} \mathrm{CA}$ compared with DM0. This is due to the lower cetane number and high latent heat of vaporization of methanol increasing the ignition delay, thereby increasing the maximum combustion pressure. In addition, methanol burns faster than diesel. Therefore, the addition of methanol can increase the cylinder pressure.

Figure 5a-d shows the effect of methanol-diesel mixtures with different ratios on the engine in-cylinder temperature at different speeds. It can be seen that with the increase of the ratio of methanol in the mixed fuel, the overall temperature in the cylinder shows a downward trend. When the engine speed is $2000 \mathrm{rpm}$, the maximum cylinder temperature of DM0 is $1147.15 \mathrm{~K}$, and the maximum cylinder temperatures of DM10, DM20, DM30, and DM40 are $1150.26 \mathrm{~K}, 1153.18 \mathrm{~K}, 1156.17 \mathrm{~K}$, and $1157.2 \mathrm{~K}$, respectively. This is because the high oxygen content of methanol promotes the combustion of fuel in the cylinder at the early stage of combustion, which makes the cylinder temperature rise. However, the cylinder temperature of DM0 is the highest in the later stage of combustion, followed by DM10, DM20, DM30, and DM40. This is due to the calorific value of methanol being lower than that of diesel, which generates less heat and makes the cylinder temperature lower. 

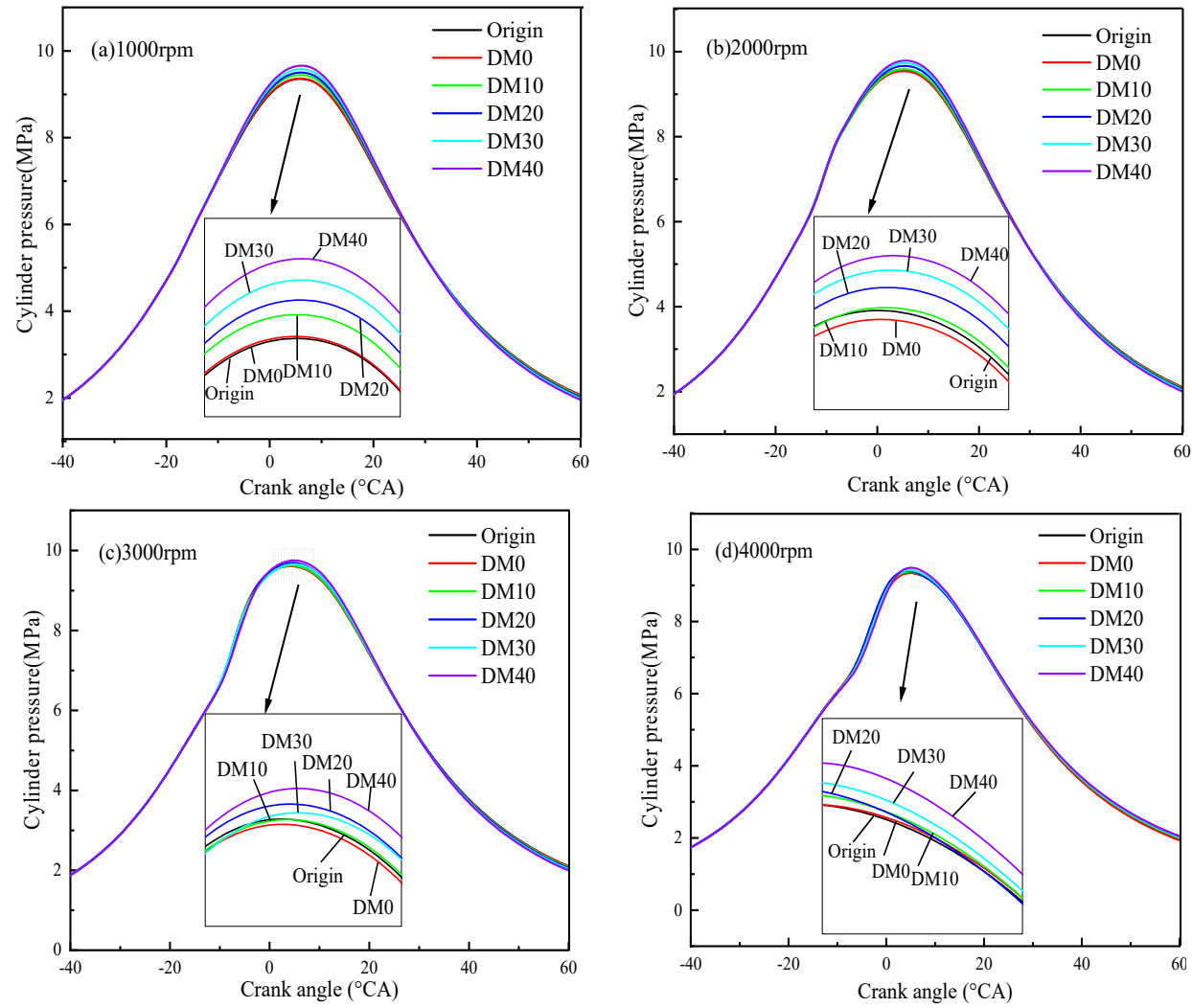

Figure 4. Effect of different ratios of methanol-diesel mixtures on engine in-cylinder pressure at different speeds.
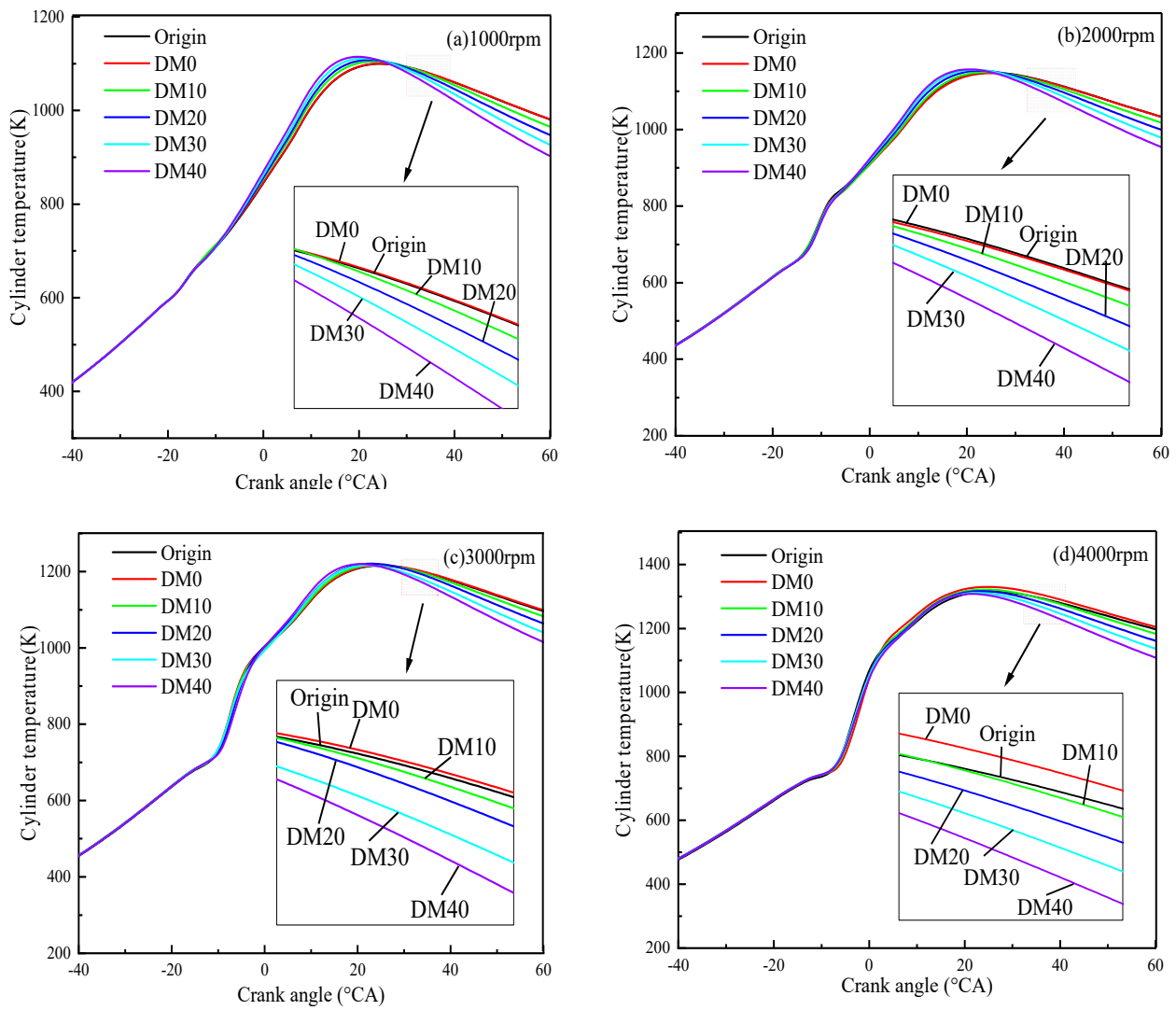

Figure 5. Effect of different ratios of methanol-diesel mixtures on engine in-cylinder temperature at different speeds. 
It can be seen from Figures 4 and 5 that the pure diesel model (with DOC, i.e., origin curve) has only slight changes in both in-cylinder pressure and in-cylinder temperature compared with the modified pure diesel model (with DOC + DPF + SCR, i.e., DM0 curve). This is caused by exhaust back pressure. For example, at $3000 \mathrm{rpm}$, the origin curve is smaller than the DM0 curve, as seen in Figures $4 c$ and 5c, compared to the DM0 cylinder pressure. The presence of the aftertreatment system makes the EBP increase and causes the cylinder pressure to decrease. Similarly, the EBP becomes more extensive, and the gas is not quickly exhausted, causing the cylinder temperature to increase.

\subsection{The Engine Economic Characteristic \\ 3.2.1. Engine Power and Torque}

Figure 6 shows the effects of different ratios of methanol-diesel mixtures on the engine power and torque at different speeds. The results show that the power and torque of the engine decrease as the ratio of methanol in the methanol-diesel fuel mixture increases. In addition, the larger the ratio of methanol, the greater the decrease in power and torque performance. Compared with DM0, the power decreased by 1.07-3.76\%, 2.49-6.74\%, $4.34 \%-11.35 \%$, and $6.44 \%-15.45 \%$ for DM10, DM20, DM30, and DM40 mixtures, respectively, and the torque decreased by $1.08-3.76 \%, 2.49-6.74 \%, 4.34-11.35 \%$, and $6.34-15.45 \%$. The reason is that the calorific value of the methanol-diesel mixture is lower than DM0. In addition, methanol absorbs a large amount of heat during the vaporization process, which reduces the in-cylinder temperature. Several researchers have also shown that the power and torque performances of the engine decrease as the ratio of methanol increases $[40,41]$.

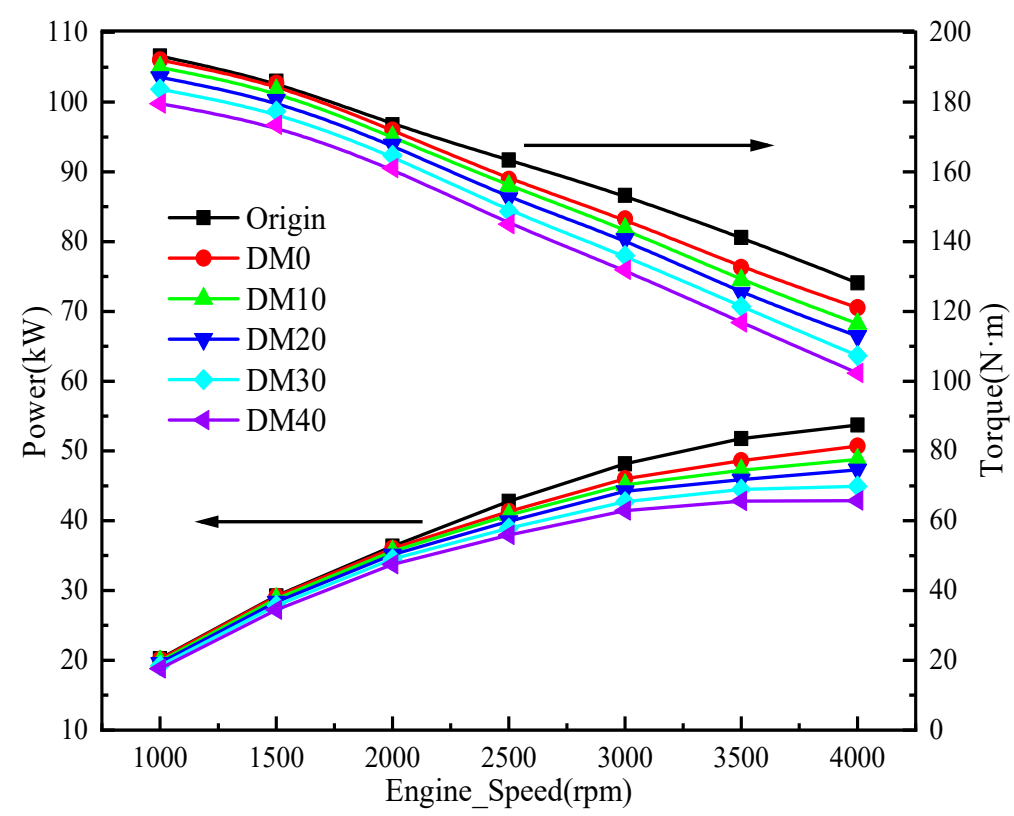

Figure 6. Effects of different ratios of methanol-diesel mixtures on engine power and torque at different speeds.

In addition, the improved model is compared with the original model (only DOC, i.e., origin curve). The results show that the increase of EBP in the origin curve decreases the engine power and torque compared with DM0, and the higher the engine speed, the greater the effects on power and torque.

\subsubsection{Brake Specific Fuel Consumption}

The brake specific fuel consumption (BSFC) is an important parameter to measure the engine performance characteristic [42,43]. The lower the fuel consumption rate, the better the economy. Figure 7 shows the effect of different ratios of methanol-diesel fuel mixtures on the BSFC at different speeds. It can be found that with the methanol ratio in the mixed 
fuel increased to $10 \%, 20 \%, 30 \%$, and $40 \%$, the brake specific fuel consumption increased by $3.77 \%, 6.92 \%, 12.33 \%$, and $17.61 \%$, respectively. Similarly, this result is consistent with that of Hasan et al. [44]. This is because the calorific value of methanol $(20.1 \mathrm{MJ} / \mathrm{kg})$ is much lower than that of diesel fuel $(42.5 \mathrm{MJ} / \mathrm{kg})$. When the ratio of methanol in the fuel increases, the overall calorific value of the fuel decreases, resulting in higher fuel consumption at the same operating conditions.

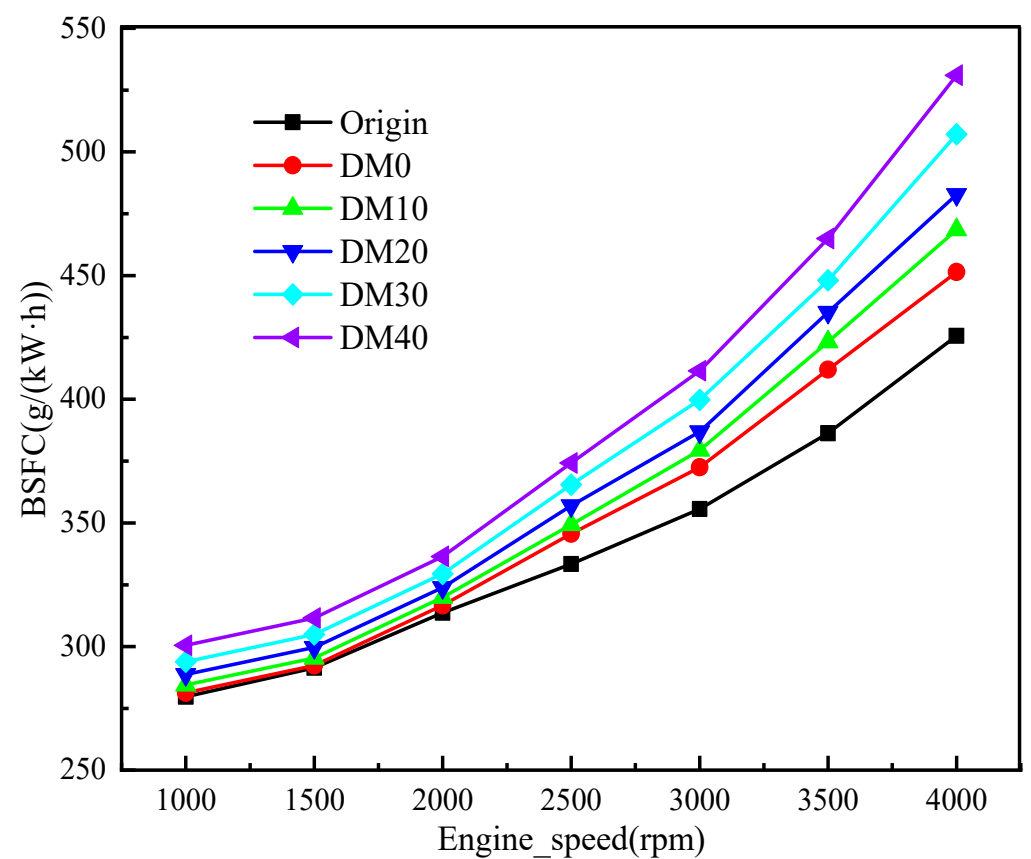

Figure 7. Effect of different ratios of methanol-diesel mixtures on BSFC at different speeds.

In addition, the origin curve compared with the DM0 curve can be seen in the Figure 7. It can be seen that the improved model fuel consumption is larger than the original model. Moreover, the higher the speed is, the greater the fuel consumption is. The fuel consumption increases from $0.58 \%$ to $6.07 \%$ when the speed increases from $1000 \mathrm{rmp}$ to $4000 \mathrm{rmp}$. The reason is that with the rise of EBP, the exhaust gas from the upward piston increases, and the exhaust gas in the cylinder rises, which is not conducive to in-cylinder combustion. This finally leads to an increase in fuel consumption and the deterioration of the engine economy.

\subsubsection{Brake Thermal Efficiency}

The brake thermal efficiency (BTE) values for different fuels are compared at different speeds and shown in Figure 8. The following equation calculates the BTE:

$$
B T E=\frac{3600}{B S F C \cdot L C V}
$$

where $L C V$ is the lower heating value of fuel, $\mathrm{MJ} / \mathrm{kg}$.

Figure 8 shows the effect of different ratios of methanol-diesel mixtures on the brake thermal efficiency of the engine at different speeds. It can be seen that the BTE increases with the increase of the ratio of methanol in the methanol-diesel mixture fuel. This is because the high oxygen content of methanol itself can alleviate the local oxygen deficiency in diesel engines during diffusion combustion. In addition, the micro-explosion phenomenon occurs in methanol-diesel fuel mixtures [45]. The larger the ratio of methanol, the more pronounced the micro-explosion phenomenon is, which improves the overall combustion phenomenon and compensates for the reducing calorific value. The kinematic viscosity of the mixture fuel is shown in Table 1. As a result, the BTE becomes larger. 


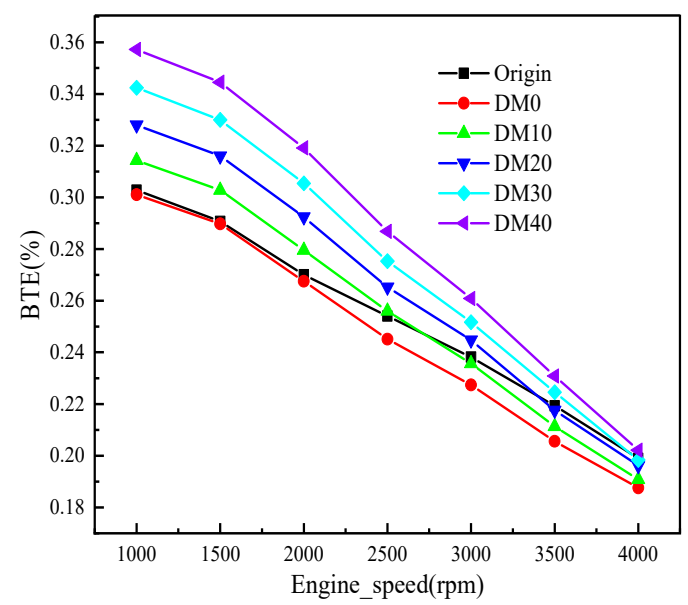

Figure 8. Effect of different ratios of methanol-diesel mixtures on BTE at different speed.

\subsection{The Engine Emissions Characteristics}

\subsubsection{Soot Emission}

Figure 9 shows the effect of different ratios of methanol-diesel mixtures on soot emission at different speeds. It can be seen that the soot emission gradually increases with the increase of engine speed. However, the soot emission gradually decreases when the ratio of methanol in the fuel increases. For example, at $3000 \mathrm{rpm}$, with the methanol ratio in the mixed fuel increased to $10 \%, 20 \%, 30 \%$, and $40 \%$, the soot emission decreased by $0.25 \%, 8.69 \%, 16.81 \%$, and $25.28 \%$, respectively. When the engine speed increases, the cycle time of each combustion process is shortened, and there is not enough time for soot oxidation. Therefore, the soot emission increases with increasing engine speed. However, with the increase of the methanol ratio, the oxygen content of the methanol improves the combustion effect. The higher the ratio of methanol added, the better the oxidation of soot. Zhang et al. [46] and Wei et al. [47] reached the same conclusion through research.

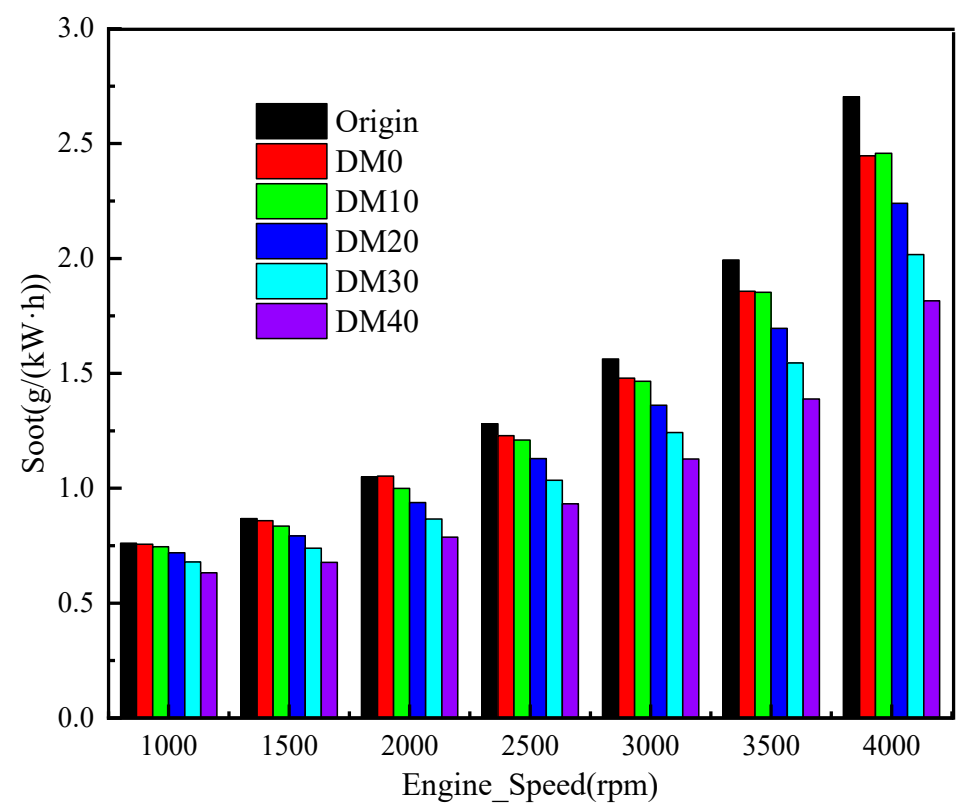

Figure 9. Effect of different ratios of methanol-diesel mixtures on soot emission at different speeds.

\subsection{2. $\mathrm{NO}_{\mathrm{x}}$ Emission}

Figure 10 shows the effect of different ratios of methanol-diesel mixtures on $\mathrm{NO}_{x}$ emission at different speeds. It can be seen that $\mathrm{NO}_{\mathrm{x}}$ emission increases with the increase of engine speed. In addition, it can be found that the rate of $\mathrm{NO}_{\mathrm{x}}$ generation decreases with 
the increase of methanol ratio. At the same operation time, the reduction of rate indicates that the amount of $\mathrm{NO}_{x}$ decreases. At high speeds, with the increase of methanol, the decreased rate of $\mathrm{NO}_{\mathrm{x}}$ increases. Compared with pure diesel DM0, the $\mathrm{NO}_{\mathrm{x}}$ generation rate of DM20, DM30, and DM40 methanol-diesel mixtures decreased by $1.65 \%, 4.90 \%$, and $8.25 \%$, respectively, at the rated speed of $4000 \mathrm{rpm}$, while DM10 increased by $1.18 \%$. The reason is that $\mathrm{NO}_{\mathrm{x}}$ is generated under the condition of high temperature and rich oxygen. Because methanol is an oxygenated fuel, when the methanol concentration is low, the $\mathrm{NO}_{\mathrm{x}}$ emission is promoted. However, as the concentration of methanol increases, the latent heat of vaporization of methanol is greater than that of diesel fuel, which inhibits the generation of $\mathrm{NO}_{\mathrm{x}}$. In addition, the combustion rate of methanol is faster than that of diesel, which shortens the combustion time and helps to inhibit $\mathrm{NO}_{\mathrm{x}}$ generation. Similar conclusions were reached by Yao et al. [12].

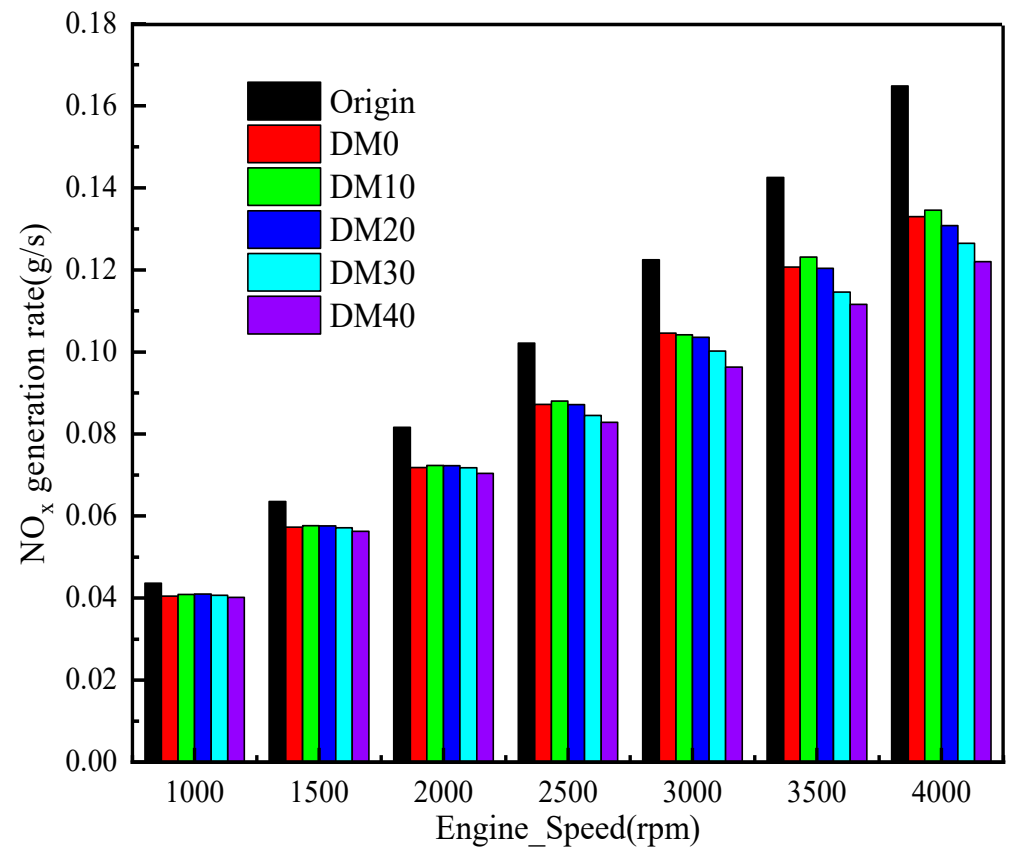

Figure 10. Effect of different ratios of methanol-diesel mixtures on $\mathrm{NO}_{\mathrm{x}}$ generation rate at different speeds.

\subsubsection{CO Emission}

Figure 11 shows the effect of different ratios of methanol-diesel mixtures on $\mathrm{CO}$ emission at different speeds. It can be seen that the $\mathrm{CO}$ emission increases with the increase of engine speed. However, it decreased with the increase of methanol ratio. For example, at $4000 \mathrm{rpm}$, compared with DM0, the CO emission is decreased by $56.59 \%$. At medium and low speeds, CO emission is slightly higher than DM0. This is mainly due to the higher latent heat of vaporization and higher auto-ignition temperature of methanol fuel, which leads to incomplete combustion of the fuel. However, methanol is an oxygenated fuel, and oxygen atoms play a significant role in combustion. At medium and high speed, a "micro explosion" of the methanol-diesel mixture may occur, which is helpful to the atomization of the mixture. As a result, $\mathrm{CO}$ emission tends to decrease with the increase of the methanol ratio. These results are consistent with those of other researchers [48-50]. 


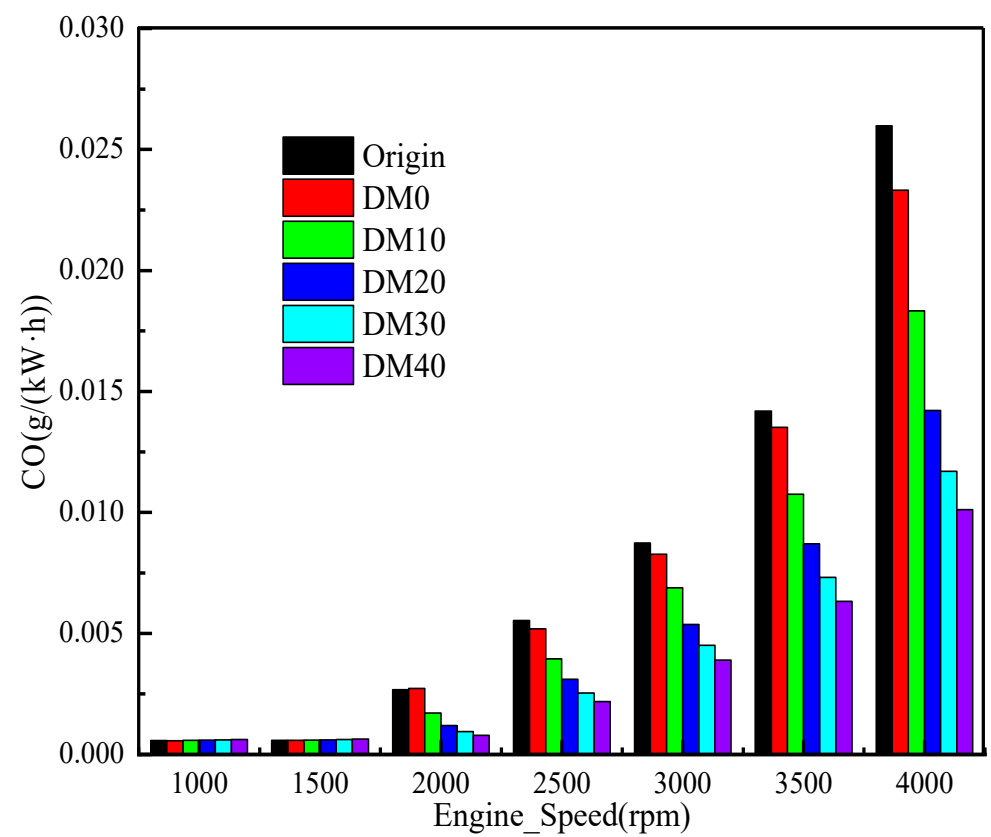

Figure 11. Effect of different ratios of methanol-diesel mixtures on CO emission at different speeds.

\subsubsection{HC Emission}

Figure 12 shows the effect of different ratios of methanol-diesel mixtures on $\mathrm{HC}$ emission at different speeds. It can be seen that the $\mathrm{HC}$ emission decreases with the increase of engine speed. The higher the engine speed, the lower the emission. In addition, it can be found that the $\mathrm{HC}$ emission increases with the increase of the methanol ratio. For example, at $1000 \mathrm{rpm}$, compared with DM0, the HC emission of DM40 increases by $14.24 \%$. This is because the latent heat of vaporization of methanol can significantly reduce the in-cylinder combustion temperature, which leads to an increase of the quench effect [51] and an increase of unburned HC emission. However, with the increase of rotational speed and the cylinder temperature, the latent heat of vaporization of methanol decreases and HC emission decreases. These results were consistent with Wei et al. [52] when they studied methanol mixed fuels.

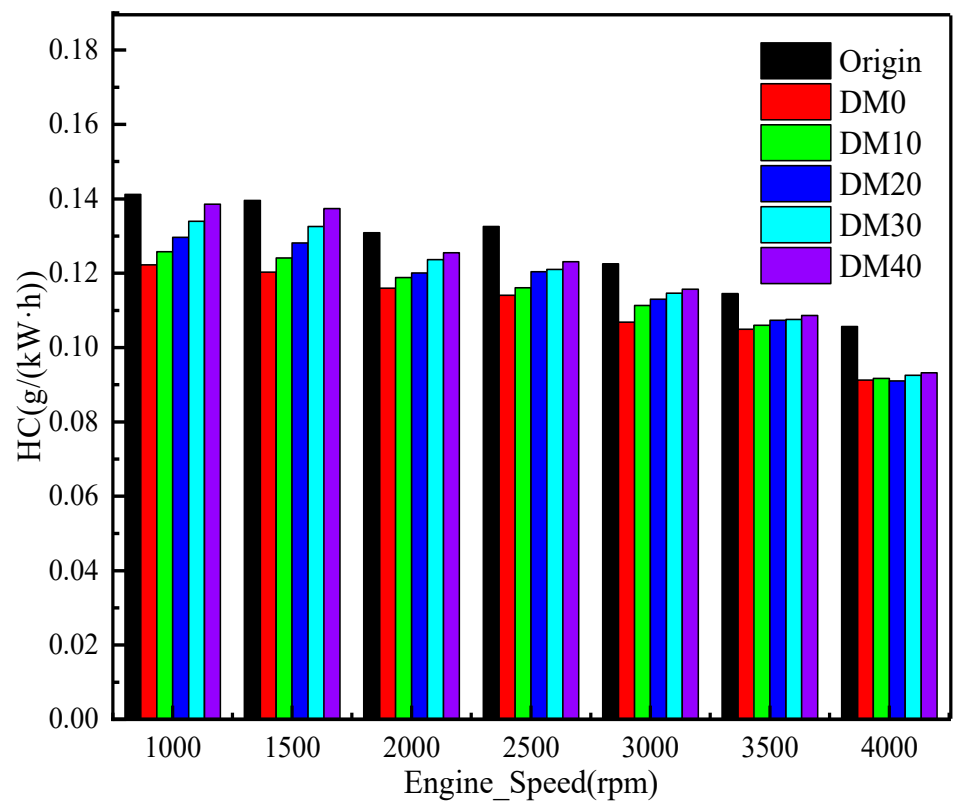

Figure 12. Effect of different ratios of methanol-diesel mixtures on HC emission at different speeds. 
In addition, it is also compared with the model without improvement (DOC only, black part in the Figure 12). Figures 9-12 clearly show that the DM0 curve is lower than the origin curve regarding soot emission, $\mathrm{NO}_{\mathrm{x}}$ generation rate, $\mathrm{CO}$ emission, and $\mathrm{HC}$ emission. This is due to the existence of a DPF + SCR system, which increases EBP and leads to more residual exhaust gas in the cylinder and a higher temperature in the cylinder. It is conducive to fuel atomization, evaporation, and cylinder combustion, reducing $\mathrm{CO}$ emission, $\mathrm{HC}$ emission, $\mathrm{NO}_{\mathrm{x}}$ emission, and soot emission. Therefore, on the whole, the improved model is more beneficial to improve the combustion and emission characteristics of the engine.

\section{Conclusions}

Nowadays, with the rapid developments of the economy and industrial automation, the shortage of resources (such as non-renewable energy, oil [53], and coal [54]) and environmental pollution (air pollution [55] and human health [56]) are becoming more and more serious [57]. How to effectively control energy shortage [58-63] and engine emission reduction [64-74] are the main areas of interest for researchers today. In this paper, an improved model was developed using AVL-BOOST software and employed to investigate the effects of methanol-diesel with different methanol ratios (DM0, DM10, DM20, DM30, and DM40) on engine combustion and emission characteristics at different speeds. The main conclusions are as follows:

(1) The addition of methanol improves the combustion characteristic of the diesel engine. More specifically, the addition of methanol makes the fuel mass in the premixing period increase. Moreover, the addition of methanol accelerates the combustion rate of the fuel mixture and shortens the combustion time. As a result, the cylinder pressure is increased, and the cylinder temperature is decreased.

(2) The increase in BSFC is because as the methanol content increases, it increases the engine delay period. Moreover, the low calorific value of methanol increases fuel consumption and leads to poor engine economy. Likewise, the high oxygen content of methanol causes the BTE to become larger.

(3) The addition of methanol decreases the emissions of soot, $\mathrm{NO}_{x}$, and $\mathrm{CO}$. The high oxygen content of methanol allows complete combustion of the fuel, which leads to the decrease of soot and $\mathrm{CO}$ emissions. In addition, the latent heat of vaporization of methanol is large, and the diffusion rate and combustion rate are more significant than that of diesel, which shortens the combustion time and inhibits the generation of $\mathrm{NO}_{\mathrm{x}}$.

(4) The addition of methanol increases the HC emission. The decrease in the in-cylinder combustion temperature increases the quenching effect and increases the $\mathrm{HC}$ emission. However, due to the increase of EBP of the improved model, the HC emission is decreased, and the $\mathrm{CO}$, soot, and $\mathrm{NO}_{\mathrm{x}}$ emissions are decreased.

In general, the addition of methanol to the improved model (DOC + DPF + SCR) can effectively improve the combustion and emission characteristics of the engine. It should be emphasized that this strategy can be considered as a fundamental approach to enhance environment-friendly aspects. For further study, the combustion and emission characteristics of the methanol-diesel engine will be investigated in more depth using a more accurate 3D computational fluid dynamics (CFD) model in future work.

Author Contributions: Conceptualization, Z.Z., J.L. (Jianbin Luo), Y.J. and S.C.; methodology, Z.Z., Y.J. and S.C.; software, J.T., J.L. (Jiangtao Li); validation, Z.Z., J.L. (Jianbin Luo), J.T. and D.Y.; formal analysis, J.L. (Jianbin Luo), Z.Z. and S.C.; investigation, J.L. (Jianbin Luo), Y.J. and S.C.; resources, J.L. (Jianbin Luo) and S.C.; data curation, J.L. (Jianbin Luo), H.J.; writing-original draft preparation, J.L. (Jianbin Luo), D.T. and S.C.; writing-review and editing, J.L. (Jianbin Luo), D.T., Y.J. and S.C.; visualization, J.L. (Jianbin Luo) and S.C.; supervision, J.L. (Jianbin Luo) and S.C.; project administration, Z.Z. and S.C.; funding acquisition, Z.Z. All authors have read and agreed to the published version of the manuscript. 
Funding: This work is supported by the Guangxi Basic Ability Improving Programs of 2020KY39008 and 2020KY08015, the Key Scientific Research Projects of Guangxi Vocational \& Technical Institute of Industry (2019015KY025), the Guangxi Special Program for Young Talents Guike (AD20159066) and the Guangxi University of Science and Technology Doctoral Fund under the research grants of $20 \mathrm{Z} 22$ and $20 \mathrm{~S} 04$.

Institutional Review Board Statement: Not applicable.

Informed Consent Statement: Not applicable.

Data Availability Statement: All data used to support the findings of this study are included within the article.

Acknowledgments: This work is supported by the Guangxi Basic Ability Improving Programs of 2020KY39008 and 2020KY08015, the Key Scientific Research Projects of Guangxi Vocational \& Technical Institute of Industry (2019015KY025), the Guangxi Special Program for Young Talents Guike (AD20159066) and the Guangxi University of Science and Technology Doctoral Fund under the research grants of $20 \mathrm{Z} 22$ and $20 \mathrm{~S} 04$.

Conflicts of Interest: The authors declare that they have no conflict of interests regarding the publication of this paper.

\section{References}

1. Cai, T.; Becker Sid, M.; Cao, F.; Wang, B.; Tang, A.; Fu, J.; Han, L.; Sun, Y.; Zhao, D. NO Emission performance assessment on a perforated plate-implemented premixed ammonia-oxygen micro-combustion system. Chem. Eng. J. 2021, 417, 128033. [CrossRef]

2. Cai, T.; Zhao, D.; Wang, B.; Li, J.; Guan, Y. $\mathrm{NO}_{\mathrm{x}}$ emission and thermal performances studies on premixed ammonia-oxygen combustion in a $\mathrm{CO}_{2}$-free micro-planar combustor. Fuel 2020, 280, 118554. [CrossRef]

3. Zhang, B.; Zou, H.; Huang, Z.; Tan, J.; Zuo, Q. Endpoint forecast of different diesel-biodiesel soot filtration process in diesel particulate filters considering ash deposition. Fuel 2020, 272, 117678. [CrossRef]

4. Jiaqiang, E.; Liu, G.; Zhang, Z.; Han, D.; Chen, J.; Wei, K.; Gong, J.; Yin, Z. Effect analysis on cold starting performance enhancement of a diesel engine fueled with biodiesel fuel based on an improved thermodynamic model. Appl. Energy 2019, 243, 321-335.

5. Ye, J.; Lv, J.; Tan, D.; Ai, Z.; Feng, Z. Numerical Analysis on Enhancing Spray Performance of SCR Mixer Device and Heat Transfer Performance Based on Field Synergy Principle. Processes 2021, 9, 786. [CrossRef]

6. Jiaqiang, E.; Zhao, M.; Zuo, Q.; Zhang, B.; Zhiqing, Z.; Peng, Q.; Han, D.; Zhao, X.; Deng, Y. Effects analysis on diesel soot continuous regeneration performance of a rotary microwave-assisted regeneration diesel particulate filter. Fuel 2020, 260, 116353.

7. Cai, T.; Zhao, D. Effects of fuel composition and wall thermal conductivity on thermal and $\mathrm{NO}_{\mathrm{x}}$ emission performances of an ammonia/hydrogen-oxygen micro-power system. Fuel Process. Technol. 2020, 209, 106527. [CrossRef]

8. Zhang, Z.; Ye, J.; Tan, D.; Feng, Z.; Luo, J.; Tan, Y.; Huang, Y. The effects of $\mathrm{Fe}_{2} \mathrm{O}_{3}$ based DOC and SCR catalyst on the combustion and emission characteristics of a diesel engine fueled with biodiesel. Fuel 2021, 290, 120039. [CrossRef]

9. Jiaqiang, E.; Zhao, X.; Qiu, L.; Zhang, Z.; Han, D.; Deng, Y. Experimental investigation on performance and economy characteristics of a diesel engine with variable nozzle turbocharger and its application in urban bus. Energy Convers. Manag. 2019, 193, 149-161.

10. Gong, C.; Lib, Z.; Huang, K.; Liu, F. Research on the performance of a hydrogen/methanol dual-injection assisted spark-ignition engine using late-injection strategy for methanol. Fuel 2020, 260, 116403. [CrossRef]

11. Gong, C.; Yia, L.; Zhang, Z.; Sund, J.; Liu, F. Assessment of ultra-lean burn characteristics for a stratified-charge direct-injection spark-ignition methanol engine under different high compression ratios. Appl. Energy 2020, 261, 114478. [CrossRef]

12. Yao, C. Reduction of Smoke and $\mathrm{NO}_{\mathrm{x}}$ from Diesel Engines using Diesel/Methanol Compound Combustion System. Energy Fuels 2007, 21, 686-691. [CrossRef]

13. Berber, A. The effect of Diesel-Methanol Blends with Volumetric Ratios on the Performance and Emissions of a Diesel Engine. Mechanika 2019, 25, 363-369. [CrossRef]

14. Zang, R.; Yao, C. Numerical Study of Combustion and Emission Characteristics of a Diesel/Methanol Dual Fuel (DMDF) Engine. Energy Fuels 2015, 29, 3963-3971. [CrossRef]

15. Zhang, Z.; Jiaqiang, E.; Deng, Y.; Pham, M.; Zuo, W.; Peng, Q.; Yin, Z. Effects of fatty acid methyl esters proportion on combustion and emission characteristics of a biodiesel fueled marine diesel engine. Energy Convers. Manag. 2018, 159, 244-253. [CrossRef]

16. Cong, S.; Garner, C.; McTaggart-Cowan, G. The Effects of Exhaust Back Pressure on Conventional and Low-Temperature Diesel Combustion, Proceedings of the Institution of Mechanical Engineers. J. Automob. Eng. 2011, 225, 222-235. [CrossRef]

17. Cai, T.; Zhao, D.; Sun, Y.; Ni, S.; Li, W. Evaluation of $\mathrm{NO}_{x}$ Emission Characteristics in a $\mathrm{CO}_{2}$-Free Micro-Power System by Implementing a Perforated Plate. Renew. Sustain. Energy Rev. 2021, 145, 111150. [CrossRef]

18. Herreros, J.M.; Gill, S.S.; Lefort, I.; Tsolakis, A.; Millington, P.; Moss, E. Enhancing the low temperature oxidation performance over a Pt and a Pt-Pd diesel oxidation catalyst. Appl. Catal. B Environ. 2014, 147, 835-841. [CrossRef] 
19. Franken, T.; Vieweger, E.; Klimera, A.; Hug, M.; Heel, A. Sulphur tolerant diesel oxidation catalysts by noble metal alloying. Catal. Commun. 2019, 129, 105732. [CrossRef]

20. Fayad, M.A.; Tsolakis, A.; Fernández-Rodríguez, D.; Herreros, J.M.; Martos, F.J.; Lapuerta, M. Manipulating modern diesel engine particulate emission characteristics through butanol fuel blending and fuel injection strategies for efficient diesel oxidation catalysts. Appl. Energy 2017, 190, 490-500. [CrossRef]

21. Serrano, J.R.; Arnau, F.J.; Martín, J.; Auñón, Á. Development of a Variable Valve Actuation Control to Improve Diesel Oxidation Catalyst Efficiency and Emission in a Light Duty Diesel Engine. Energies 2020, 13, 4561. [CrossRef]

22. Liang, Y.; Ding, X.; Wang, J.; Zhao, M.; Dan, Y.; Jiang, L.; Chen, Y. Catalytic performance promoted on Pt-based diesel oxidation catalyst assisted by polyvinyl alcohol. Environ. Sci. Pollut. Res. 2020, 27, 41824-41838. [CrossRef] [PubMed]

23. Liang, Y.; Ding, X.; Dai, J.; Zhao, M.; Zhong, L.; Wang, J.; Chen, Y. Active oxygen-promoted NO catalytic on monolithic Pt-based diesel oxidation catalyst modified with Ce. Catal. Today 2019, 327, 64-72. [CrossRef]

24. Zhao, D.; Guan, Y.; Reinecke, A. Characterizing hydrogen-fuelled pulsating combustion on thermodynamic properties of a combustor. Commun. Phys. 2019, 2, 44. [CrossRef]

25. Liu, T.; Jiaqiang, E.; Yang, W.; Hui, A.; Cai, H. Development of a skeletal mechanism for biodiesel blend surrogates with varying fatty acid methyl esters ratio. Appl. Energy 2016, 162, 278-288. [CrossRef]

26. Imdadul, H.K.; Masjuki, H.H.; Kalam, M.A.; Zulkifli, N.W.M.; Alabdulkarem, A.; Rashed, M.M.; Teoh, Y.H.; How, H.G. Higher alcohol-biodiesel-diesel blends: An approach for improving the performance, emission, and combustion of a light-duty diesel engine. Energy Convers. Manag. 2016, 111, 174-185. [CrossRef]

27. Xu, H.; Liu, S.; Wang, Y.; Lin, Q.; Lin, C.; Lan, L.; Wang, Q.; Chen, Y. Promotional effect of $\mathrm{Al}_{2} \mathrm{O}_{3}$ on $\mathrm{WO}_{3} / \mathrm{CeO}_{2}-\mathrm{ZrO}_{2}$ monolithic catalyst for selective catalytic reduction of nitrogen oxides with ammonia after hydrothermal aging treatment. Appl. Surf. Sci. 2018, 427, 656-669. [CrossRef]

28. Zhang, Z.; Jiaqiang, E.; Chen, J.; Zhao, X.; Zhang, B.; Deng, Y.; Peng, Q.; Yin, Z. Effects of boiling heat transfer on the performance enhancement of a medium speed diesel engine fueled with diesel and rapeseed methyl ester. Appl. Therm. Eng. 2020, 169, 114984. [CrossRef]

29. Lan, Q.; Bai, Y.; Fan, L.; Gu, Y.; Wen, L.; Yang, L. Investigation on fuel injection quantity of low-speed diesel engine fuel system based on response surface prediction model. Energy 2020, 211, 118946. [CrossRef]

30. Nikzadfar, K.; Shamekhi, A. Investigating the relative contribution of operational parameters on performance and emissions of a common-rail diesel engine using neural network. Fuel 2014, 125, 116-128. [CrossRef]

31. Yang, Y.; Dec, J.; Dronniou, N.; Sjöberg, M. Tailoring HCCI heat-release rates with partial fuel stratification: Comparison of two-stage and single-stage-ignition fuels. Proc. Combust. Inst. 2011, 33, 3047-3055. [CrossRef]

32. Yu, W.; Zhang, Z.; Liu, B. Investigation on the Performance Enhancement and Emission Reduction of a Biodiesel Fueled Diesel Engine Based on an Improved Entire Diesel Engine Simulation Model. Processes 2021, 9, 568. [CrossRef]

33. Tan, D.; Chen, Z.; Li, J.; Luo, J.; Yang, D.; Cui, S.; Zhang, Z. Effects of Swirl and Boiling Heat Transfer on the Performance Enhancement and Emission Reduction for a Medium Diesel Engine Fueled with Biodiesel. Processes 2021, 9, 568. [CrossRef]

34. Souza, G.; Pellegrini, C.; Ferreira, S.; Soto, P.; Armas, O. Study of intake manifolds of an internal combustion enine: A new geometry based on experimental results and numerical simulations. Therm. Sci. Eng. Prog. 2019, 9, 248-258. [CrossRef]

35. Salek, F.; Babaie, M.; Hosseini, S.V.; Beg, O.A. Multi-objective optimization of the engine performance and emissions for a hydrogen/gasoline dual-fuel engine equipped with the port water injection system. Int. J. Hydrog. Energy 2021, 46, 10535-10547. [CrossRef]

36. Onorati, A.; Ferrari, G.; D'Errico, G. 1D Unsteady Flows with Chemical Reactions in the Exhaust Duct-System of SI. Engines: Predictions and Experiments. SAE Trans. 2001, 110, 738-752.

37. Schubiger, R.A.; Boulouchos, K.; Eberle, M.K. Russbildung und Oxidation bei der dieselmotorischen Verbrennung. Motortechnische Zeitschrift 2002, 63, 342-353. [CrossRef]

38. D'Errico, G.; Ferrari, G.; Onorati, A.; Cerri, T. Modeling the Pollutant Emissions from a S.I. Engine. SAE Tech. Pap. 2002, 111, 1-11.

39. Pan, M.; Huang, R.; Liao, J.; Jia, C.; Zhou, X.; Huang, H.; Huang, X. Experimental study of the spray, combustion, and emission performance of a diesel engine with high n-pentanol blending ratios. Energy Convers. Manag. 2019, 194, 1-10. [CrossRef]

40. Zhang, Z.; Jiaqiang, E.; Chen, J.; Zhu, H.; Zhao, X.; Han, D.; Zuo, W.; Peng, Q.; Gong, J.; Yin, Z. Effects of low-level water addition on spray, combustion and emission characteristics of a medium speed diesel engine fueled with biodiesel fuel. Fuel 2019, 239, 245-262. [CrossRef]

41. Chu, W. The Experimental Study About the Influence of Methanol/Diesel Fuel Mixture on Diesel Engine Performance. In Proceedings of the Workshop on Power Electronics \& Intelligent Transportation System (IEEE), Guangzhou, China, 2-3 August 2008.

42. Devarajan, Y.; Munuswamy, D.; Nagappan, B.; Subbiah, G. Experimental assessment of performance and exhaust emission characteristics of a diesel engine fuelled with Punnai biodiesel/butanol fuel blends. Pet. Sci. 2019, 16, 1471-1478. [CrossRef]

43. Justin Abraham Baby, S.; Suresh Babu, S.; Devarajan, Y. Performance study of neat biodiesel-gas fuelled diesel engine. Int. J. Ambient. Energy 2018, 42, 269-273. [CrossRef]

44. Hasan, A.; Osman, A.; Al-Muhtaseb, A.; Al-Rawashdeh, H.; Abu Jrai, A.; Ahmad, R.; Behiri, M.; Deka, T.J.; Rooney, D. An experimental study of engine characteristics and tailpipe emissions from modern DI diesel engine fuelled with methanol/diesel blends. Fuel Process. Technol. 2021, 220, 106901. [CrossRef] 
45. Zhang, C.; Li, G.; Li, Y. Effects of Co-Combustion Ratio on Rapid Combustion, Cyclical Variation and Emission of a Heavy-Duty Diesel Engine Fueled with Diesel-Methanol Dual-Fuel. Environ. Prog. Sustain. Energy 2017, 1528-1536. [CrossRef]

46. Zhang, Z.H.; Cheung, C.s.; Yao, C. Influence of fumigation methanol on the combustion and particulate emissions of a diesel engine. Fuel 2013, 11, 442-448. [CrossRef]

47. Wei, J.; Yin, Z.; Wang, C.; Lv, G.; Zhuang, Y.; Xiangrong, L.; Wu, H. Impact of aluminium oxide nanoparticles as an additive in diesel-methanol blends on a modern DI diesel engine. Appl. Therm. Eng. 2020, 185, 116372. [CrossRef]

48. Jiaqiang, E.; Pham, M.; Zhao, D.; Deng, Y.; Le, D.; Zuo, W.; Zhu, H.; Liu, T.; Peng, Q.; Zhang, Z. Effect of different technologies on combustion and emissions of the diesel engine fueled with biodiesel: A review. Renew. Sustain. Energy Rev. 2017, 80, 620-647.

49. Sayin, C. Engine performance and exhaust gas emissions of methanol and ethanol-diesel blends. Fuel 2010, 89, 3410-3415. [CrossRef]

50. Yerrennagoudaru, H.; Kondekal, M.; Raza, A.; Kantharaj, B.R.; Mujahed, A.; Irshad, K. Analysis and comparison of performance and emissions of compression ignition engine fuelled with diesel and different bio-fuels blended with methanol. Mater. Today Proc. 2018, 5, 5175-5185. [CrossRef]

51. Cai, X.; Wang, J.; Jiang, X.; Ling, J.; Xu, Y.; Gao, Z. Effect of heat-treatment on LiZn ferrite hollow microspheres prepared by self-reactive quenching technology. Appl. Phys. Eng. 2018, 19, 409-416. [CrossRef]

52. Wei, L.; Cheung, C.S.; Ning, Z. Effects of biodiesel-ethanol and biodiesel-butanol blends on the combustion, performance and emissions of a diesel. Energy 2018, 155, 957-970. [CrossRef]

53. Yu, W.; Zhang, Z.; Liu, B. Effect Analysis on the Performance Enhancement and Emission Reduction of Diesel Engine Fueled with Biodiesel Fuel Based on an Improved Model. Int. J. Aerosp. Eng. 2020, 2020, 8831376. [CrossRef]

54. Zhao, L.; Su, X.; Wang, X. Comparative study of exhaust gas recirculation (EGR) and hydrogen-enriched EGR employed in a SI engine fueled by biobutanol-gasoline. Fuel 2020, 268, 117194. [CrossRef]

55. Cai, T.; Zhao, D. Mitigating $\mathrm{NO}_{x}$ emission from an ammonia-fueled micro-power system with a perforated plate implemented. $J$. Hazard. Mater. 2021, 401, 123848. [CrossRef]

56. Zhao, D.; Gutmark, E.; Goey, P. A review of cavity-based trapped vortex, ultra-compact, high-g, inter-turbine combustors. Prog. Energy Combust. Sci. 2017, 66, 42-82. [CrossRef]

57. Cai, T.; Sun, Y.; Zhao, D. Enhancing heat transfer performance analyses of a hydrogen-fueled meso-combustor with staggered bluff-bodies. Fuel Process. Technol. 2021, 218, 106867. [CrossRef]

58. Sawatmongkhon, B.; Theinnoi, K.; Wongchang, T.; Haoharn, C.; Wongkhorsub, C.; Sukjit, E.; Tsolakis, A. Catalytic oxidation of diesel particulate matter by using silver and ceria supported on alumina as the oxidation catalyst. Appl. Catal. A Gen. 2019, 574, 33-40. [CrossRef]

59. Zuo, H.; Tan, J.; Wei, K.; Huang, Z.; Zhong, D.; Xie, F. Effects of different poses and wind speeds on wind-induced vibration characteristics of a dish solar concentrator system. Renew. Energy 2021, 168, 1308-1326. [CrossRef]

60. Zuo, H.; Liu, G.; Jiaqiang, E.; Zuo, W.; Wei, K.; Hu, W.; Tan, J.; Zhong, D. Catastrophic analysis on the stability of a large dish solar thermal power generation system with wind-induced vibration. Sol. Energy 2019, 183, 40-49. [CrossRef]

61. Hu, L.; Hu, X.; Che, Y.; Feng, F.; Lin, X.; Zhang, Z. Reliable state of charge estimation of battery packs using fuzzy adaptive federated filtering. Appl. Energy 2020, 262, 114569. [CrossRef]

62. Zhang, F.; Liao, G.; Jiaqiang, E.; Chen, J.; Leng, E. Comparative study on the thermodynamic and economic performance of novel absorption power cycles driven by the waste heat from a supercritical $\mathrm{CO}_{2}$ cycle. Energy Convers. Manag. 2021, $228,113671$. [CrossRef]

63. Peng, Q.; Yang, W.; Jiaqiang, E.; Li, Z.; Xu, H.; Fu, G.; Li, S. Investigation on $\mathrm{H}_{2}$ /air combustion with $\mathrm{C}_{3} \mathrm{H}_{8}$ addition in the combustor with part/full porous medium. Energy Convers. Manag. 2020, 228, 113652. [CrossRef]

64. Wu, G.; Wu, D.; Li, Y.; Meng, L. Effect of Acetone-n-Butanol-Ethanol (ABE) as an Oxygenate on Combustion, Performance, and Emission Characteristics of a Spark Ignition Engine. J. Chem. 2020, 2020, 1-11. [CrossRef]

65. Jiaqiang, E.; Zhang, Z.; Chen, J.; Pham, M.; Zhao, X.; Peng, Q.; Zhang, B.; Yin, Z. Performance and emission evaluation of a marine diesel engine fueled by water biodiesel-diesel emulsion blends with a fuel additive of a cerium oxide nanoparticle. Energy Convers. Manag. 2018, 169, 194-205.

66. Peng, Q.; Yang, W.; Jiaqiang, E.; Li, S.; Li, Z.; Xu, H.; Fu, G. Effects of propane addition and burner scale on the combustion characteristics and working performance. Appl. Energy 2021, 285, 116484. [CrossRef]

67. Wu, G.; Wang, X.; Abubakar, S.; Li, Y.; Liu, Z. A realistic skeletal mechanism for the oxidation of biodiesel surrogate composed of long carbon chain and polyunsaturated compounds. Fuel 2021, 289, 119934. [CrossRef]

68. Xie, Y.; Zuo, Q.; Wang, M.; Wei, K.; Zhang, B.; Chen, W.; Tang, Y.; Wang, Z.; Zhu, G. Effects analysis on soot combustion performance enhancement of an improved catalytic gasoline particulate filter regeneration system with electric heating. Fuel 2021, 290, 119975. [CrossRef]

69. Xie, Y.; Zuo, Q.; Zhu, G.; Guan, Q.; Wei, K.; Zhang, B.; Tang, Y.; Shen, Z. Investigations on the soot combustion performance enhancement of an improved catalytic gasoline particulate filter regeneration system under different electric heating powers. Fuel 2021, 283, 119301. [CrossRef]

70. Li, W.; Ji, J.; Huang, L.; Guo, Z. Global dynamics of a controlled discontinuous diffusive SIR epidemic system. Appl. Math. Lett. 2021, 121, 107420. [CrossRef] 
71. Zhang, B.; Jiaqiang, E.; Gong, J.; Yuan, W.; Zuo, W.; Li, Y.; Fu, J. Multidisciplinary design optimization of the diesel particulate filter in the composite regeneration process. Appl. Energy 2016, 181, 14-28. [CrossRef]

72. Zuo, Q.; Xie, Y.; Jiaqiang, E.; Zhu, X.; Zhang, B.; Tang, Y.; Zhu, G.; Wang, Z.; Zhang, J. Effect of different exhaust parameters on NO conversion efficiency enhancement of a dual-carrier catalytic converter in the gasoline engine. Energy 2020, 191, 116521. [CrossRef]

73. Hu, L.; Bao, X.; Lin, M.; Yu, C.; Wang, F. Research on risky driving behavior evaluation model based on CIDAS real data. Proc. Inst. Mech. Eng. Part D J. Automob. Eng. 2021, 235, 2176-2187. [CrossRef]

74. Hu, L.; Hu, X.; Kuang, A.; Lin, M.; Wang, J. Casualty risk of e-bike rider struck by passenger vehicle using China In- depth accident data. Traffic Inj. Prev. 2020, 21, 283-287. [CrossRef] [PubMed] 